Repository of the Max Delbrück Center for Molecular Medicine (MDC) Berlin (Germany)

http://edoc.molc-berlin.de/8955/

Chimeric Polyomavirus-Derived Virus-Like Particles: The Immunogenicity of an Inserted Peptide Applied without Adjuvant to Mice Depends on Its Insertion Site and Its Flanking Linker Sequence

Robert Lawatscheck, Egle Aleksaite, Jörg A. Schenk, Burkhard Micheel, Burkhard Jandrig, Gudrun Holland, Kestutis Sasnauskas, Alma Gedvilaite, Rainer G. Ulrich

This is a copy of an article published in the "Viral Immunology" (c) 2007 copyright Mary Ann Liebert, Inc.; "Viral Immunology" is available online at: http://online.liebertpub.com. 


\title{
Chimeric Polyomavirus-Derived Virus-Like Particles: The Immunogenicity of an Inserted Peptide Applied without Adjuvant to Mice Depends on Its Insertion Site and Its Flanking Linker Sequence
}

\author{
ROBERT LAWATSCHECK, ${ }^{1, *}$ EGLE ALEKSAITE, 2 * JÖRG A. SCHENK, ${ }^{1}$ \\ BURKHARD MICHEEL, ${ }^{1}$ BURKHARD JANDRIG ${ }^{3}$ GUDRUN HOLLAND, ${ }^{4}$ \\ KESTUTIS SASNAUSKAS, ${ }^{2}$ ALMA GEDVILAITE, ${ }^{2}$ and RAINER G. ULRICH ${ }^{5}$
}

\begin{abstract}
We inserted the sequence of the carcinoembryonic antigen-derived T cell epitope CAP-1-6D (CEA) into different positions of the hamster polyomavirus major capsid protein VP1. Independently from additional flanking linkers, yeast-expressed VP1 proteins harboring the CEA insertion between VP1 amino acid residues 80 and 89 (site 1) or 288 and 295 (site 4) or simultaneously at both positions assembled to chimeric virus-like particles (VLPs). BALB/c mice immunized with adjuvant-free VLPs developed VP1- and epitope-specific antibodies. The level of the CEA-specific antibody response was determined by the insertion site, the number of inserts, and the flanking linker. The strongest CEAspecific antibody response was observed in mice immunized with VP1 proteins harboring the CEA insert at site 1. Moreover, the CEA-specific antibodies in these mice were still detectable 6 mo after the final booster immunization. Our results indicate that hamster polyomavirus-derived VLPs represent a highly immunogenic carrier for foreign insertions that might be useful for clinical and therapeutic applications.
\end{abstract}

\section{INTRODUCTION}

$\mathbf{V}$ IRUS-LIKE PARTICLES (VLPs) produced by heterologous synthesis of viral structural proteins resemble native infectious virions in their structural and immunological properties, but are noninfectious because they lack viral nucleic acid. The strong immunogenicity of VLPs is reflected not only in the induction of antibody but also helper $\mathrm{T}$ and cytotoxic $\mathrm{T}$ lymphocyte (CTL) responses.
Therefore, VLPs have become promising vaccine candidates against a large number of human and animal virus infections. Thus VLPs based on hepatitis B virus and human papillomavirus antigens are already in use in humans as recombinant vaccines. The advantageous immunological properties of VLPs can also be transferred to foreign peptides or protein segments presented on the surface of so-called chimeric VLPs (for review see Pumpens and Grens [13]).

\footnotetext{
${ }^{1}$ University of Potsdam, Institute of Biochemistry and Biology, Department of Biotechnology, Potsdam-Golm, Germany.

${ }^{2}$ Institute of Biotechnology, Vilnius, Lithuania.

${ }^{3}$ Max Delbrueck Center for Molecular Medicine, Department of Tumor Genetics, Berlin, Germany.

${ }^{4}$ Robert Koch-Institut, Berlin, Germany.

${ }^{5}$ Friedrich-Loeffler-Institut, Institute for Novel and Emerging Infectious Diseases, Greifswald-Insel Riems, Germany.

*Both authors contributed equally to this work.
} 
Although the capsid of polyomaviruses consists of the major capsid protein VP1, the minor capsid proteins VP2 and VP3 and the viral double-stranded DNA, polyomavirus-derived VLPs have been generated by heterologous synthesis of VP1 alone. Expression of VP1 originating from human polyomaviruses JC and BK, murine polyomavirus (MPyV), and other mammalian and avian polyomaviruses in insect and yeast cells resulted in the formation of VLPs (see Sasnauskas et al. [16] and Tegerstedt et al. [19]). Escherichia coli-expressed VP1 pentamers of MPyV and avian polyomavirus were demonstrated to assemble to VLPs in vitro $(14,15)$.

The entire VP1 and an amino-terminal extended derivative of hamster polyomavirus $(\mathrm{HaPyV})$ expressed in E. coli, yeast Saccharomyces cerevisiae, and insect cells spontaneously formed VLPs $(17,23)$. Carboxy-terminal truncation of 21, 69, and 79 amino acid residues from yeast-expressed HaPyV-VP1 also allowed the formation of VLPs resembling the electron microscopic image of authentic VLPs (5). A single insertion of a 5-amino acidlong foreign peptide at site 1 (between amino acids 80 and 89), 2 (between amino acids 222 and 225), 3 (between amino acids 243 and 247), or 4 (between amino acids 288 and 295) confirmed their predicted flexibility and surface exposure on VP1 (7). Scanning of these four predicted surface-exposed regions with 45- and 120amino acid-long foreign protein segments confirmed sites 1 and 4 as preferential insertion sites for longer foreign protein segments (8). The peptides and protein segments presented on VLPs were demonstrated to induce a strong antibody and $\mathrm{T}$ cell response in mice, even when applied without additional adjuvant $(7,8)$.

Recombinant polyomavirus-derived VLPs are promising tools for virus diagnostics and seroepidemiological studies $(18,25)$ as well as gene therapy and vaccine development $(3,20)$. HaPyV-VP1-derived VLPs have been demonstrated to represent a useful tool for the generation of monoclonal antibodies (mAbs) of desired epitope specificity (26). This conclusion was based on an approach with VLPs harboring two copies of a CTL epitope originating from human mucin 1 protein $(\mathrm{VP} 1 / 1,4 \mathrm{~L}-$ MUC1). To generate MUC1-specific antibodies, mice were immunized with VP1/1,4L-MUC1 VLPs, using Freund's complete adjuvant for primary immunization. Therefore, the objectives of the present study were to prove a potential optimization of this system by investigating the influence of the insertion site, the number of foreign inserts, and the additional insertion of a flexible linker on the assembly capacity of VP1 fusion proteins and their immunogenicity in mice. As a model epitope for these investigations the nonamer peptide sequence CAP-1-6D (in the following, CEA [24]) was selected. This $\mathrm{T}$ cell peptide is derived from the carcinoembryonic antigen, which is expressed in high concentration in sev- eral epithelial tumors and represents a target for immunotherapy (9).

\section{MATERIALS AND METHODS}

\section{Generation of VP1 expression plasmids}

The generation of plasmids pVP1-1, pVP1-2, pVP1-3, and pVP1-4 allowing insertions into the VP1-encoding sequence at sites $1,2,3$, and 4 , respectively, was described previously (7). Novel expression vectors were generated by modifying sites $1,2,3$, and 4 in these plasmids by introduction of Gly-Ser-Ser-Gly-encoding linkers on both sides of the $B g l I I$ insertion site (see Fig. 1A).

An oligonucleotide duplex encoding the 9-amino acidlong CEA peptide was generated by hybridization of
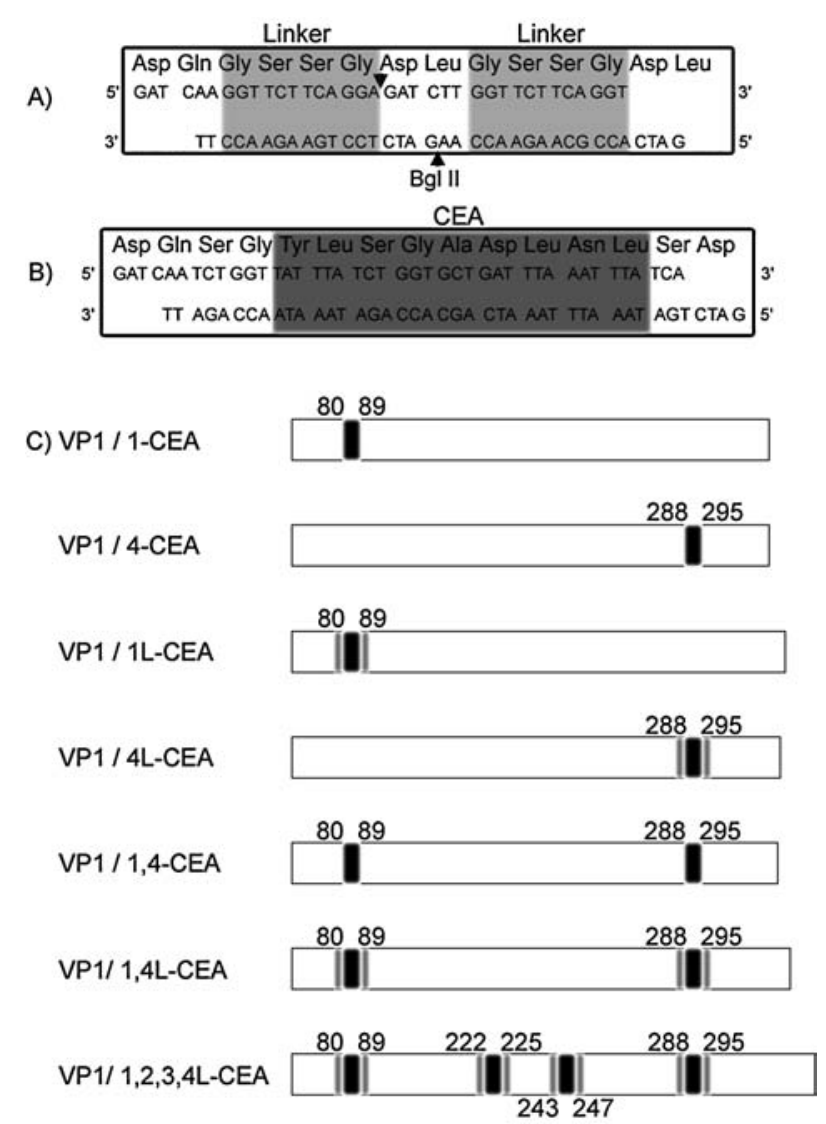

FIG. 1. Schematic presentation of the VP1 proteins harboring carcinoembryonic antigen-derived peptide CAP-1-6D (CEA) at various insertion sites. The unique $B g l$ II insertion site in the VP1-encoding sequence was modified by insertion of a linker sequence (A). The CEA peptide-encoding sequence was generated as an oligonucleotide duplex (B). The CEA-encoding duplex was inserted into sites 1 and 4 of the nonmodified or into sites 1, 2, 3, and 4 of the linker-bearing VP1-encoding sequence $(\mathbf{C})$. 
oligonucleotides CEA-5' and CEA-3', purchased from Metabion (Martinsried, Germany; Fig. 1B). This oligonucleotide duplex was inserted into the VP1-encoding sequence at various positions, resulting in seven VP1/CEA fusion-encoding constructs (Fig. 1C).

Finally, these chimeric VP1 protein-encoding sequences were confirmed by DNA sequence analysis and subsequently subcloned into the unique $X b a \mathrm{I}$ site of the yeast expression vector $\mathrm{pFX} 7$ (17).

\section{Expression and purification of VPI fusion proteins}

The $\mathrm{pFX} 7$-derived yeast expression plasmids and control plasmid pFX7-VP1/2-12 encoding the authentic HaPyV-VP1 (17) were transformed into S. cerevisiae strain AH22-214 (MATa leu2 his4). Cultivation of yeast cells and protein expression and purification were performed as previously described (7). All purified proteins were dialyzed against phosphate-buffered saline (PBS), lyophilized, and stored at $-20^{\circ} \mathrm{C}$ until further use.

\section{Sodium dodecyl sulfate-polyacrylamide gel electrophoresis and immunoblot analysis}

Crude yeast lysates or cesium chloride $(\mathrm{CsCl})$ gradient fractions were separated in a sodium dodecyl sulfate (SDS) $-12.5 \%$ polyacrylamide gel and stained with Coomassie Brilliant Blue or blotted onto a nitrocellulose membrane (PROTRAN NC BA3; Schleicher \& Schuell, Dassel, Germany) by a semidry procedure. The membrane was blocked overnight with PBS-5\% neonatal calf serum (NCS) and incubated with VP1-specific mAbs 6D11, 3D10, and 9F11 (26), diluted in PBS-NCS to a final concentration of about $1 \mu \mathrm{g} / \mathrm{mL}$, or with polyclonal mouse serum raised against native carcinoembryonic antigen (11), diluted to $1: 400$, for $1 \mathrm{~h}$ at room temperature. After washing twice with PBS- $0.5 \%$ Tween 20 (PBST), the membrane was incubated with horseradish peroxidase (HRP)-conjugated goat anti-mouse IgG (diluted 1:10,000 in PBS-NCS; Dianova, Hamburg, Germany) for $1 \mathrm{~h}$ at room temperature. The membrane was washed three times with PBST and stained with diaminobenzidine (DAB $[0.8 \mathrm{mg} / \mathrm{mL}], \mathrm{NiCl}_{2}[0.4 \mathrm{mg} / \mathrm{mL}]$, and $0.01 \% \mathrm{H}_{2} \mathrm{O}_{2}$ in $100 \mathrm{mM}$ Tris- $\mathrm{HCl}$ [pH 7.5]) according to standard protocols.

As molecular mass marker the PageRuler prestained protein ladder (SM0671; Fermentas, Vilnius, Lithuania) was used.

\section{Electron microscopy}

Diluted suspensions from $\mathrm{CsCl}$ gradient fractions after ultracentrifugation were placed on 400-mesh Pioloform-covered and carbon-coated copper grids. The sam- ples were negatively stained with $1 \%$ aqueous uranyl acetate solution and examined with a Zeiss CEM 902 electron microscope.

\section{Immunizations}

Three 6-mo-old BALB/c mice in each group were intraperitoneally immunized with $100 \mu \mathrm{g}$ of the VP1/CEA constructs in $150 \mu \mathrm{L}$ of PBS without any adjuvant. Six weeks later, this immunization was repeated with the same amount of the corresponding VP1/CEA constructs, respectively. Another $7 \mathrm{~d}$ later, blood was taken from the retro-orbital sinus of each mouse and the serum was checked for the appearance of antibodies against VP1 and the inserted peptide. For analysis of the long-lasting immunity serum samples were taken 6 mo after the final booster immunization.

\section{Enzyme-linked immunosorbent assay}

The CEA peptide (CAP-1-6D; amino acid sequence YLSGADLNL) was conjugated to bovine serum albumin (BSA) by the glutardialdehyde method (10). For indirect enzyme-linked immunosorbent assay (ELISA), microtiter plates (Greiner, Frickenhausen, Germany) were coated overnight with $5 \mu \mathrm{g}$ of VP1, BSA, or CEA peptide conjugated to BSA, in PBS. After blocking with 3\% BSA, mouse sera, diluted from 1:300 to 1:218,000 for VP1 and to 1:9600 for CEA peptide and BSA in 3\% BSA, were applied to the plate for $60 \mathrm{~min}$ at room temperature. The wells were washed with tap water and incubated with HRPconjugated rabbit anti-mouse immunoglobulin (Dako, Glostrup, Denmark) for $60 \mathrm{~min}$. After extensive washing with tap water, color development was achieved with substrate solution containing tetramethyl benzidine (TMB) and urea-conjugated hydrogen peroxide in sodium dihydrogen phosphate buffer, $\mathrm{pH}$ 5.6. The reaction was stopped with $50 \mu \mathrm{L}$ of $1 \mathrm{M} \mathrm{H}_{2} \mathrm{SO}_{4}$ and optical densities were measured at $450 \mathrm{~nm}$ with a microplate reader.

\section{RESULTS}

\section{Generation of VP1/CEA fusion proteins}

For expression in S. cerevisiae, seven different pFX7derived constructs encoding VP1 fusion proteins with CEA (CAP-1-6D) inserts were generated (Fig. 1C). After cultivation and induction of foreign protein synthesis, yeast lysates were generated and subjected to sucrose cushion ultracentrifugation and subsequent twice $\mathrm{CsCl}$ gradient centrifugation. SDS-PAGE analysis of $\mathrm{CsCl}$ gradient fractions revealed for all constructs the presence of full-length VP1 fusion proteins (Fig. 2A, lanes 1-7) larger than the original VP1 (Fig. 2A, lane 8; about 42 

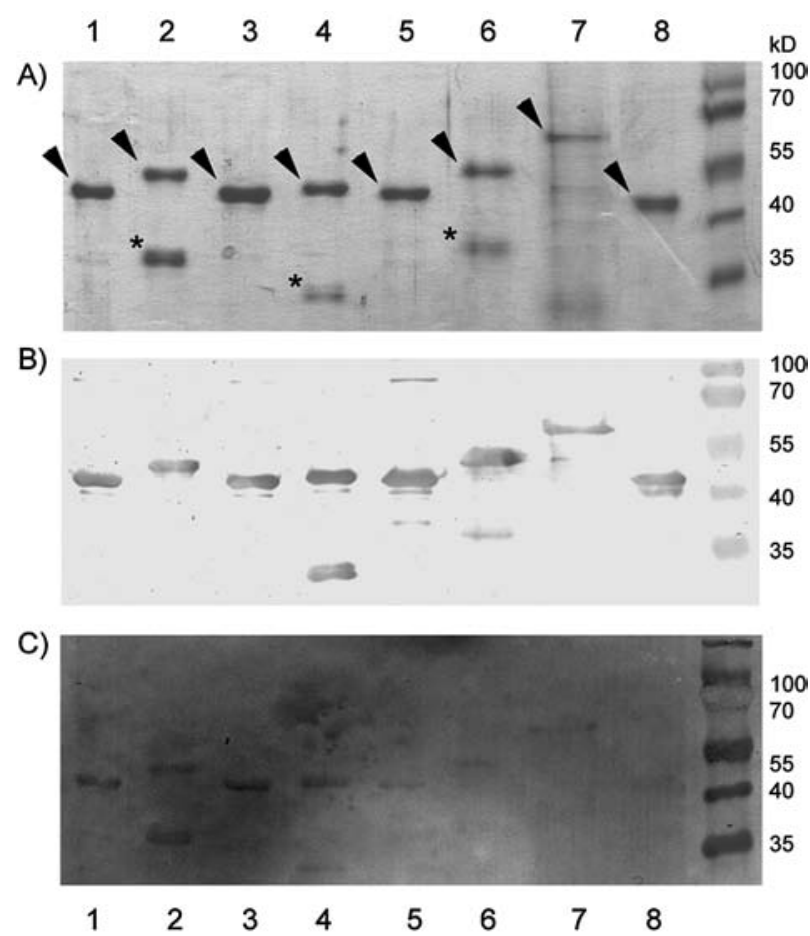

FIG. 2. Detection of VP1/CEA fusion proteins after cesium chloride density gradient centrifugation by SDS-PAGE (A) and immunoblot analysis using VP1-specific monoclonal antibody 6D11 (B) and polyclonal mouse serum raised against native carcinoembryonic antigen $(\mathbf{C})$. Aliquots of gradient fractions from yeast cells expressing VP1/1-CEA (lane 1), VP1/1L-CEA (lane 2), VP1/4-CEA (lane 3), VP1/4L-CEA (lane 4), VP1/1,4-CEA (lane 5), VP1/1,4L-CEA (lane 6), VP1/1,2,3,4L-CEA (lane 7), and wild-type VP1 (lane 8) were applied to a $12.5 \%$ SDS-polyacrylamide gel. Full-sized fusion proteins are marked by arrowheads and shorter degradation products are indicated by asterisks.

$\mathrm{kDa}$ ). In general, the observed migration of the fusion proteins corresponded to the respective predicted molecular masses. However, the observed molecular masses of the linker-containing VP1/CEA fusion proteins, and of VP1/1,2,3,4L-CEA in particular, were much larger than expected, most likely reflecting yeast-mediated posttranslational modifications of the recombinant proteins. All fusion proteins, except VP1/1,2,3,4L-CEA, resembled VP1 in their quantity and purity in SDS-PAGE after second $\mathrm{CsCl}$ gradient purification. Smaller defined degradation products were observed exclusively in fractions of VP1/1L-CEA, VP1/4L-CEA, and VP1/1,4L-CEA (Fig. 2A, lanes 2, 4, and 6; labeled with an asterisk).

\section{Antigenic characterization of VP1/CEA fusion proteins}

Immunoblot analysis confirmed the expression of VP1 derivatives by specific reaction with VP1-specific mAb
6D11 (Fig. 2B) and with mAbs 3D10 and 9F11 (data not shown) for all constructs tested, except VP1/1,2,3,4LCEA. In line with our previous epitope mapping data (26), this fusion protein was detected by mAbs 6D11 and 3D10, but failed to react with mAb 9F11 because of the destruction of its binding site (amino acids 223/224) by CEA insertion. Thus, all full-sized VP1 fusion proteins contain an intact amino terminus with amino acids 1-64 and amino acids 59-152 of VP1 representing the epitope regions of mAbs 6D11 and 3D10, respectively (26). The full-sized VP1/CEA fusion proteins were also detected by a mouse serum raised against native carcinoembryonic antigen (Fig. 2C). The observed low reactivity might be due to the short segment of carcinoembryonic antigen presented on VLPs as well as differences in the amino acid sequence and posttranslational modifications of the CEA peptide used here and that of the native carcinoembryonic antigen used for the generation of the polyclonal antiserum. The degradation products observed in the SDS-PAGE for VP1/1LCEA, VP1/4L-CEA, and VP1/1,4L-CEA were found to be reactive with $\mathrm{mAb} 9 \mathrm{~F} 11$ (data not shown). This leads to the conclusion that these VP1-derived smaller protein bands resulted from degradation processes most likely induced by linker insertion. Additional immunoblot data demonstrated differences in their antigenicity; the smaller derivatives of VP1/4L-CEA (about $30 \mathrm{kDa}$ ) and VP1/1,4LCEA (about $36 \mathrm{kDa}$ ) were recognized by mAbs 6D11 (Fig. 2B, lanes 4 and 6, respectively) and 3D10 (data not shown), whereas the VP1/1L-CEA product (about $35 \mathrm{kDa}$ ) failed to react with both mAbs (Fig. $2 \mathrm{~B}$, lane 2; and data not shown). In contrast to this lack of reactivity of the smaller product of VP1/1L-CEA with anti-VP1 antibodies, it was detected by the mouse serum raised against native carcinoembryonic antigen (Fig. 2C, lane 2). As the epitopes of both $\mathrm{mAbs}$ are located in the amino-terminal region of VP1, the larger fragment of VP1/1L-CEA is lacking the amino-terminal part, probably close to the position of the first insertion site at amino acid 80. These data imply that the region spanning amino acids 59-80 may represent an essential part of the epitope region of mAb 3D10.

\section{Analysis of the assembly capacity of VP1/CEA fusion proteins}

The major peak of VP1 antigenicity was recovered for almost all VP1/CEA fusion proteins in a fraction of the final $\mathrm{CsCl}$ density gradient where wild-type VP1 was found. This migration behavior of almost all VP1/CEA fusion proteins suggested the formation of chimeric VLPs. The VP1/1,2,3,4L-CEA fusion protein was the only protein recovered in a $\mathrm{CsCl}$ gradient fraction of lower density (data not shown). Negative stain electron microscopy confirmed the assembly of VLPs for almost all VP1/CEA fusion proteins (Fig. 3A-F). All VLPs were 

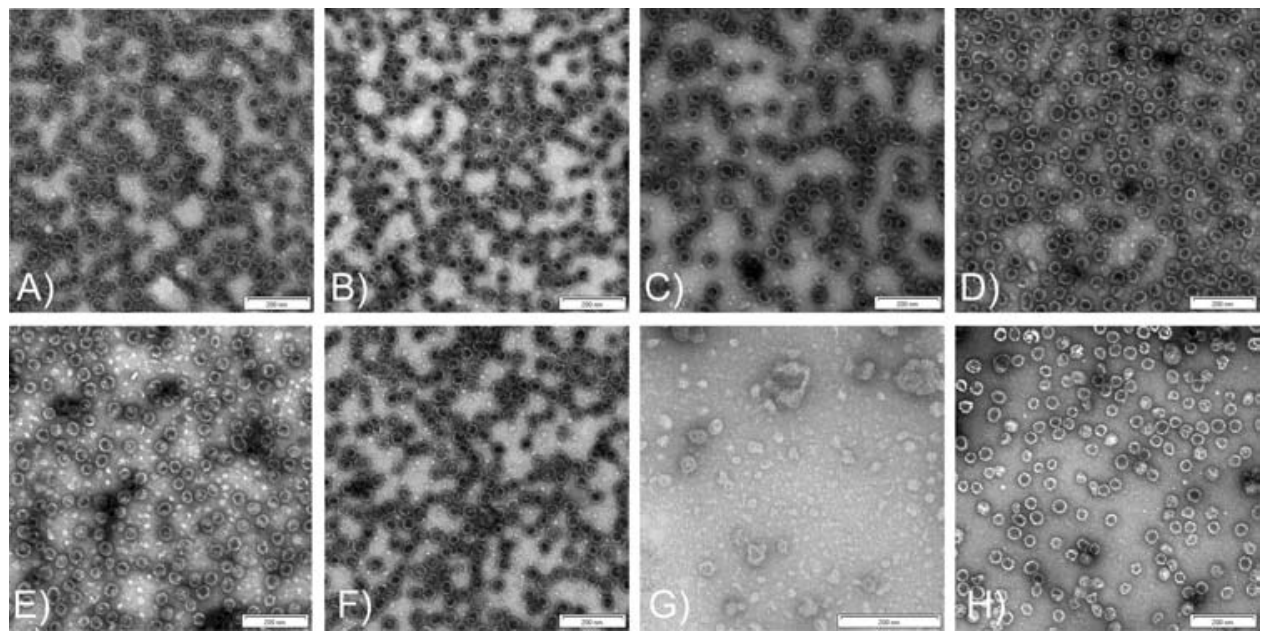

FIG. 3. Electron micrographs of gradient-purified fusion proteins VP1/1-CEA (A), VP1/1L-CEA (B), VP1/4-CEA (C), VP1/4L-CEA (D), VP1/1,4-CEA (E), VP1/1,4L-CEA (F), VP1/1,2,3,4L-CEA (G), and wild-type VP1 control (H).

found to correspond in shape and size to that of authentic VP1 (Fig. 3H). These investigations revealed no obvious differences in assembly between constructs harboring one or two CEA insertions, irrespectively of a flanking linker. Although SDS-PAGE and immunoblot analysis have proven the synthesis and successful purification of VP1/1,2,3,4L-CEA protein, electron microscopy failed to detect the formation of VLPs (Fig. 3G).

\section{Antibody response of mice against VLPs applied without adjuvant}

Three mice of each group were immunized intraperitoneally with VP1/CEA fusion proteins or VP1 alone (see Table 1) and boosted after $6 \mathrm{wk}$ with the same amount of protein. There was no adjuvant administered at any time of immunization. Seven days after the boost, blood was taken and samples were screened by indirect ELISA for VP1, BSA, or CEA peptide conjugated to BSA.

With the exception of the group immunized with VP1/1,2,3,4L-CEA, in sera from mice of all other groups immunized with chimeric VLPs, CEA-specific antibodies were detected by their reactivity with BSA-coupled CAP1-6D peptide (Table 1). In the groups immunized with VP1/1-CEA, VP1/1L-CEA, and VP1/1,4L-CEA all mice developed CEA-reactive antibodies. In contrast, in the groups immunized with VP1/4-CEA, VP1/4L-CEA, and VP1/1,4-CEA only two or one of three mice showed an CEA-specific antibody response. Furthermore, the average of the titer in the groups immunized with VP1/1CEA and VP1/1L-CEA was higher than that observed in the other groups. Whereas the linker addition influenced the immunogenicity of the insert for these constructs only slightly, its employment drastically improved the im- munogenicity of the construct harboring two CEA insertions. The lack of reactivity of sera from mice immunized with VP1 alone confirmed the specificity of the CAP16D ELISA (Table 1).

All mice immunized with VP1-derived VLPs developed VP1-specific antibodies, except those immunized with VP1/1,2,3,4L-CEA (Table 1). In comparison with wild-type VP1, all VP1 responses induced by VP1/CEA VLPs were decreased. The immunization of mice with linker-bearing constructs resulted in higher titers of VP1specific antibodies. In addition, the anti-VP1 responses of mice immunized with fusion proteins with only one insert were superior to those with two inserts.

To prove the induction of long-lasting immunity, sera from mice immunized with the most immunogenic VLPs (VP1/1-CEA, VP1/1L-CEA, and VP1/1,4L-CEA) were taken $6 \mathrm{mo}$ after the final booster immunization and tested for VP1- and CEA-specific antibodies (Table 1). All mice immunized with chimeric VLPs demonstrated the presence of CEA-specific antibodies with the highest titer being found in animals immunized with VP1/1-CEA VLPs. In these animals the levels of the titers of anti-CEA and anti-VP1 antibodies after 6 mo were only moderately reduced compared with the titers of antibodies analyzed 1 wk after the final booster immunization. The reduction of the titers of CEA- and VP1-specific antibodies in the animals immunized with VP1/1L-CEA and VP1/1,4LCEA was larger.

\section{DISCUSSION}

The assembly capacity of a VLP carrier system and the immunogenicity of a foreign epitope presented on these VLPs can be influenced by the number and length of in- 
Table 1. EliSA Reactivity of Sera from Mice Immunized with Chimeric VP1/CEA VLPs 1 Week and 6 Months after Final Booster Immunization

\begin{tabular}{|c|c|c|c|c|c|}
\hline \multirow{3}{*}{$\begin{array}{l}\text { Antigen used for } \\
\text { immunization }\end{array}$} & \multirow{3}{*}{$\begin{array}{l}\text { Animal } \\
\text { number }\end{array}$} & \multicolumn{4}{|c|}{ ELISA end-point titers ${ }^{\mathrm{a}}$ for } \\
\hline & & \multicolumn{2}{|c|}{$V P 1$} & \multicolumn{2}{|c|}{$C A P 1-6 D-B S A$} \\
\hline & & $1 w k$ & $6 \mathrm{mo}$ & $1 w k$ & $6 \mathrm{mo}$ \\
\hline \multirow[t]{3}{*}{ VP1/1-CEA } & 1 & 24,300 & 20,000 & 2,400 & 2,000 \\
\hline & 2 & 8,100 & n.d. & 2,400 & n.d. \\
\hline & 3 & 24,300 & 20,000 & $\geq 9,600$ & 3,000 \\
\hline \multirow[t]{3}{*}{ VP1/1L-CEA } & 4 & 24,300 & 10,000 & 4,800 & 600 \\
\hline & 5 & 24,300 & 10,000 & 600 & 300 \\
\hline & 6 & 72,900 & 20,000 & 4,800 & 600 \\
\hline \multirow[t]{3}{*}{ VP1/4-CEA } & 7 & 2,700 & n.d. & $<300$ & n.d. \\
\hline & 8 & 8,100 & n.d. & 2,400 & n.d. \\
\hline & 9 & 8,100 & n.d. & 1,200 & n.d. \\
\hline \multirow[t]{3}{*}{ VP1/4L-CEA } & 10 & 8,100 & n.d. & $<300$ & n.d. \\
\hline & 11 & 24,300 & n.d. & 600 & n.d. \\
\hline & 12 & 72,900 & n.d. & 2,400 & n.d. \\
\hline \multirow[t]{3}{*}{ VP1/1,4-CEA } & 13 & 2,700 & n.d. & $<300$ & n.d. \\
\hline & 14 & 8,100 & n.d. & 300 & n.d. \\
\hline & 15 & 900 & n.d. & $<300$ & n.d. \\
\hline \multirow[t]{3}{*}{ VP1/1,4L-CEA } & 16 & 24,300 & 5,000 & 1,200 & 300 \\
\hline & 17 & 24,300 & 5,000 & 1,200 & 300 \\
\hline & 18 & 24,300 & 5,000 & 2,400 & 300 \\
\hline \multirow[t]{3}{*}{ VP1/1,2,3,4L-CEA } & 19 & $<100$ & n.d. & $<300$ & n.d. \\
\hline & 20 & $<100$ & n.d. & $<300$ & n.d. \\
\hline & 21 & $<100$ & n.d. & $<300$ & n.d. \\
\hline \multirow[t]{3}{*}{ VP1 } & 22 & 72,900 & 10,000 & $<300$ & $<300$ \\
\hline & 23 & 72,900 & 10,000 & $<300$ & $<300$ \\
\hline & 24 & 24,300 & n.d. & $<300$ & n.d. \\
\hline
\end{tabular}

Abbreviation: n.d., not determined.

${ }^{\mathrm{a}}$ Given are the reciprocal titers where an OD of $\geq 0.4$ was observed.

serts, and their position in the carrier moiety and its surrounding region. The HaPyV-VP1 carrier was previously demonstrated to have a large insertion capacity for foreign sequences (8). Site 4 of HaPyV-VP1 even tolerated the insertion of an enhanced green fluorescent protein (6). Shortsized epitopes (five amino acids in length) can be inserted as single copies into various sites of VP1 or simultaneously into sites 1 and 2 or sites 1 and 3 without disturbing the formation of chimeric VLPs (7). The investigations presented here confirmed the high insertion capacity of HaPyV-VP1 and its potential to tolerate a simultaneous insertion of epitopes into various sites of the same VP1 molecule, thereby increasing the epitope copy number per VLP. In line with data on a VP1/1,2,3,4L-MUC1 fusion protein (our unpublished data), the lack of assembly capacity of the VP1/1,2,3,4L-CEA fusion protein demonstrated limitations of the assembly capacity of HaPyV-VP1. Similarly, larger insertions into sites 2 and 3 resulted in an inefficient formation of VLPs (8).
Our findings imply that the position of an insert alongside the correct assembly of VLPs plays a major role in its immunogenic potential. The strongest CEA-specific antibody response was observed in mice immunized with VP1 proteins harboring the CEA insert at site 1 . This strong antibody response seems not to be influenced by additional linker insertion, suggesting a highly flexible property of the insert at this site. This observation is in line with our previous data for a five-amino acid-long insert (7). In contrast, the immunogenicity of 45- and 120amino acid-long inserts was found to be almost the same for insertion sites 1 and 4 (8). Although the linker also did not influence the immunogenicity of the CEA insert in position 4 , it obviously improved the immunogenicity of the VP1 fusion harboring two copies of the CEA epitope. These findings assert the prediction that the linker contributes to a better integration of the inserts in the protein, thus keeping the VP1 structure intact.

Although in general it is assumed that the epitope den- 
sity may increase the level of an antibody response, the strong immunogenicity seems to be driven mainly by the particulate structure of the antigen. Thus, the VP1/ 1,2,3,4L-CEA fusion protein, in spite of its multiple repetitions of the peptide in its structure, did not yield CAP1$6 \mathrm{D}$-specific antibodies. This may be because the structure is heavily modified and no assembly is possible as shown by electron microscopy. Therefore, the presence of intact assembled virus-like particles is necessary to generate an immune response, at least when protein is administered without adjuvant.

The studies presented here demonstrate that HaPyVVP1-derived VLPs can replace the effect of an adjuvant generally necessary when immunizing with an isolated antigen. This is in line with our previous data on chimeric HaPyV-VP1 VLPs harboring 45-, 80-, and 120-amino acid-long segments of a hantavirus nucleocapsid protein (8). This adjuvant effect has also been demonstrated for VLPs of other origin $(1,4)$. It is assumed today that an adjuvant activates the first steps in a response against a foreign substance, that is, the activation of an antigenpresenting cell that then activates $T$ cells. Similar events are initiated when an infectious agent is entering a vertebrate organism. Such foreign and potentially dangerous agents contain pathogen-associated molecular patterns (PAMPs) that are recognized by pattern-recognizing receptors (e.g., Toll-like receptors [TLRs]). Studies on MPyV and MPyV-derived VLPs suggested a role for TLR-2 and TLR-4 in the induction of innate immune responses and tumor susceptibility/resistance of various mouse strains (22).

VLPs represent promising vaccine candidates for application in humans. Thus, VLPs of different origin are able to induce maturation of human monocyte-derived dendritic cells (DCs) and strong T cell immunity that is mediated by cross-presentation $(2,12,21)$. VP1-derived VLPs of HaPyV and MPyV were demonstrated in vitro to induce maturation of human DCs and the induction of a CD8-positive CTL response in vitro (6). This immunogenic potential was also transferred to a MUC1CTL epitope presented on HaPyV-VP1-derived VLPs (D.C. Dorn, personal communication). The long-lasting immunity observed in this paper for mice immunized with VP1/1-CEA VLPs confirmed the unique immunogenic properties of the HaPyV-VP1-derived VLP carrier.

In conclusion, we found position 1 in HaPyV-VP1 to be the most promising site for insertion of a short immunogenic peptide resulting in the induction of a strong and long-lasting antibody response. The use of a linker is valuable to preserve the native VP1 structure; it does not, however, play a role in boosting the immunogenicity for single-insert fusion proteins. The linker can help to reassemble the VP1 structure for VLPs with multiple inserts. The investigations confirmed the importance of the VP1 structure being intact and assembly taking place for the immunogenicity of inserted peptides. Because the VLPs used in these studies have been successfully used for many different antigens they provide a good candidate for use as a general vehicle for adjuvant-free immunization of humans and other vertebrates against a wide variety of antigens.

\section{ACKNOWLEDGMENTS}

The authors acknowledge Gabriele Pecher, Siegfried Scherneck, Detlev H. Krüger, and Muhsin Özel for support during the initial stage of this work; Karin Rücker for technical assistance; Frank Sellrie for peptide conjugation; and David C. Dorn for communication of unpublished data. The VP1-specific mAbs were kindly provided by Aurelija Zvirbliene. This work was partially supported by the Internationales Büro/Bundesministerium für Forschung und Technologie, Germany (grant LTU 02/001) and by the Lithuanian Science and Study Foundation (grant V-04027).

\section{REFERENCES}

1. Deml L, Schirmbeck R, Reimann J, Wolf H, and Wagner R: Recombinant human immunodeficiency Pr55gag viruslike particles presenting chimeric envelope glycoproteins induce cytotoxic T-cells and neutralizing antibodies. Virology 1997;235:26-39.

2. Fausch SC, Da Silva DM, and Kast WM: Differential uptake and cross-presentation of human papillomavirus viruslike particles by dendritic cells and Langerhans cells. Cancer Res 2003;63:3478-3482.

3. Forstova J, Krauzewicz N, Sandig V, Elliott J, Palkova Z, Strauss M, and Griffin BE: Polyoma virus pseudocapsids as efficient carriers of heterologous DNA into mammalian cells. Hum Gene Ther 1995;6:297-306.

4. Francis MJ, Hastings GZ, Brown AL, Grace KG, Rowlands DJ, Brown F, and Clarke BE: Immunological properties of hepatitis B core antigen fusion proteins. Proc Natl Acad Sci USA 1990;87:2545-2549.

5. Gedvilaite A, Aleksaite E, Staniulis J, Ulrich R, and Sasnauskas K: Size and position of truncations in the carboxyterminal region of major capsid protein VP1 of hamster polyomavirus expressed in yeast determine its assembly capacity. Arch Virol 2006;151:1811-1825.

6. Gedvilaite A, Dorn DC, Sasnauskas K, Pecher G, Bulavaite A, Lawatscheck R, Staniulis J, Dalianis T, Ramqvist T, Schonrich G, Raftery MJ, and Ulrich R: Virus-like particles derived from major capsid protein VP1 of different polyomaviruses differ in their ability to induce maturation in human dendritic cells. Virology 2006;354:252-260. 
7. Gedvilaite A, Frommel C, Sasnauskas K, Micheel B, Ozel M, Behrsing O, Staniulis J, Jandrig B, Scherneck S, and Ulrich R: Formation of immunogenic virus-like particles by inserting epitopes into surface-exposed regions of hamster polyomavirus major capsid protein. Virology 2000; 273:21-35.

8. Gedvilaite A, Zvirbliene A, Staniulis J, Sasnauskas K, Kruger DH, and Ulrich R: Segments of Puumala hantavirus nucleocapsid protein inserted into chimeric polyomavirusderived virus-like particles induce a strong immune response in mice. Viral Immunol 2004;17:51-68.

9. Goldstein MJ, and Mitchell EP: Carcinoembryonic antigen in the staging and follow-up of patients with colorectal cancer. Cancer Invest 2005;23:338-351.

10. Hermanson G: Bioconjugate Techniques. Academic Press, San Diego, CA, 1996.

11. Jantscheff P, Bottger V, Price M, Micheel B, Kaiser G, Zotter S, Kotzsch M, Grossmann H, and Karsten U: Production and characterization of monoclonal antibodies against carcinoembryonic antigen (CEA). Biomed Biochim Acta 1991;50:1261-1267.

12. Moron VG, Rueda P, Sedlik C, and Leclerc C: In vivo, dendritic cells can cross-present virus-like particles using an endosome-to-cytosol pathway. J Immunol 2003; 171:22422250 .

13. Pumpens P, and Grens E: Artificial genes for chimeric virus-like particles. In: Artificial DNA: Methods and Applications (Fields HA, ed.). CRC Press, Boca Raton, FL, 2002, pp. 249-327.

14. Rodgers RE, Chang D, Cai X, and Consigli RA: Purification of recombinant budgerigar fledgling disease virus VP1 capsid protein and its ability for in vitro capsid assembly. J Virol 1994;68:3386-3390.

15. Salunke DM, Caspar DL, and Garcea RL: Self-assembly of purified polyomavirus capsid protein VP1. Cell 1986;46: 895-904.

16. Sasnauskas K, Bulavaite A, Hale A, Jin L, Knowles WA, Gedvilaite A, Dargeviciute A, Bartkeviciute D, Zvirbliene A, Staniulis J, Brown DW, and Ulrich R: Generation of recombinant virus-like particles of human and non-human polyomaviruses in yeast Saccharomyces cerevisiae. Intervirology 2002;45:308-317.

17. Sasnauskas K, Buzaite O, Vogel F, Jandrig B, Razanskas R, Staniulis J, Scherneck S, Kruger DH, and Ulrich R: Yeast cells allow high-level expression and formation of polyomavirus-like particles. Biol Chem 1999;380:381386.

18. Stolt A, Sasnauskas K, Koskela P, Lehtinen M, and Dillner J: Seroepidemiology of the human polyomaviruses. J Gen Virol 2003;84:1499-1504.
19. Tegerstedt K, Andreasson K, Vlastos A, Hedlund KO, Dalianis $\mathrm{T}$, and Ramqvist T: Murine pneumotropic virus VP1 virus-like particles (VLPs) bind to several cell types independent of sialic acid residues and do not serologically cross react with murine polyomavirus VP1 VLPs. J Gen Virol 2003;84:3443-3452.

20. Tegerstedt K, Franzen AV, Andreasson K, Joneberg J, Heidari S, Ramqvist T, and Dalianis T: Murine polyomavirus virus-like particles (VLPs) as vectors for gene and immune therapy and vaccines against viral infections and cancer. Anticancer Res 2005;25:2601-2608.

21. Tsunetsugu-Yokota Y, Morikawa Y, Isogai M, KawanaTachikawa A, Odawara T, Nakamura T, Grassi F, Autran $\mathrm{B}$, and Iwamoto A: Yeast-derived human immunodeficiency virus type 1 p55 gag virus-like particles activate dendritic cells (DCs) and induce perforin expression in Gagspecific $\mathrm{CD}^{+} \mathrm{T}$ cells by cross-presentation of DCs. J Virol 2003;77:10250-10259.

22. Velupillai P, Garcea RL, and Benjamin TL: Polyoma viruslike particles elicit polarized cytokine responses in APCs from tumor-susceptible and -resistant mice. J Immunol 2006;176:1148-1153.

23. Voronkova T, Kazaks A, Ose V, Oezel M, Scherneck S, Pumpens $\mathrm{P}$, and Ulrich R: Hamster polyomavirus-derived virus-like particles are able to transfer in vitro encapsidated plasmid DNA to mammalian cells. Virus Genes 2007;34: 303-314.

24. Zaremba S, Barzaga E, Zhu M, Soares N, Tsang KY, and Schlom J: Identification of an enhancer agonist cytotoxic T lymphocyte peptide from human carcinoembryonic antigen. Cancer Res 1997;57:4570-4577.

25. Zielonka A, Gedvilaite A, Ulrich R, Luschow D, Sasnauskas K, Muller H, and Johne R: Generation of viruslike particles consisting of the major capsid protein VP1 of goose hemorrhagic polyomavirus and their application in serological tests. Virus Res 2006;120:128-137.

26. Zvirbliene A, Samonskyte L, Gedvilaite A, Voronkova T, Ulrich R, and Sasnauskas K: Generation of monoclonal antibodies of desired specificity using chimeric polyomavirus-derived virus-like particles. J Immunol Methods 2006;311:57-70.

Address reprint requests to: Dr. Rainer G. Ulrich Friedrich-Loeffler-Institut Federal Research Institute for Animal Health Institute for Novel and Emerging Infectious Diseases Boddenblick 5 a D-17493 Greifswald-Insel Riems, Germany E-mail: rainer.ulrich@fli.bund.de 